\title{
Naturally-occurring missense mutations in the human growth hormone-releasing hormone receptor alter ligand binding
}

\author{
Maria Alba and Roberto Salvatori \\ Division of Endocrinology and The Ilyssa Center for Molecular and Cellular Endocrinology, The Johns Hopkins University School of Medicine, Baltimore, \\ Maryland 21287, USA \\ (Requests for offprints should be addressed to R Salvatori, Division of Endocrinology, Johns Hopkins University School of Medicine, \\ 1830 East Monument Street \#333, Baltimore, MD 21287, USA; Email: salvator@jhmi.edu)
}

\begin{abstract}
Growth hormone $(\mathrm{GH})$ releasing hormone $(\mathrm{GHRH})$ is a hypothalamic factor that stimulates $\mathrm{GH}$ secretion. It acts by activating a seven transmembrane domain $G$ proteincoupled receptor of 423 amino acids expressed by the somatotroph cells of the pituitary gland (GHRH receptor, GHRH-R). Familial isolated growth hormone deficiency (IGHD) can be caused by mutations in the GHRH-R gene both in humans and mice. We have described six disease-causing missense mutations in this gene in IGHD patients (H137L, L144H, A176V, A222E, F242C, $\mathrm{K} 329 \mathrm{E})$. These mutations are inherited as autosomal recessive traits, and cause impairment of the receptor to transmit GHRH signalling. The aim of this study is to investigate the mechanisms through which these mutations cause receptor malfunction. To this end, we
\end{abstract}

transiently expressed each mutated receptor into Chinese hamster ovary cells. Cells expressing each of the mutated receptors did not show an increase in intracellular cyclic AMP in response to GHRH. Immunoprecipitation and immunofluorescence studies indicated that the amino acid changes do not cause protein degradation, and do not alter the proper insertion of the receptor into the cell membrane. Binding studies with human ${ }^{125} \mathrm{I}-\mathrm{GHRH}$ showed that the lack of response to GHRH is due to inability of all the mutated receptors to bind the ligand. These studies demonstrate that abnormal ligand binding is a common mechanism by which naturally occurring missense mutation alter GHRH-R function.

Journal of Endocrinology (2005) 186, 515-521

\section{Introduction}

The production and secretion of growth hormone $(\mathrm{GH})$ from the anterior pituitary is stimulated by the hypothalamic growth hormone releasing hormone (GHRH) and inhibited by somatostatin (Muller et al. 1999). GHRH is secreted by the arcuate nucleus into the portal hypophyseal circulation, and causes somatotroph cells proliferation and GH synthesis and secretion by acting on a $\mathrm{G}$ protein-coupled receptor (GPCR), the GHRH receptor (GHRH-R). This is a 423 amino acid protein (an N-terminal 22 amino acid signal peptide is likely cleaved after translation), with one extracellular N-terminal domain (containing a potential $\mathrm{N}$-glycosylation site at amino acid 50), seven hydrophobic transmembrane $\alpha$-helices, and one intracellular C-terminal domain with multiple potential phosphorylation sites.

Interaction between the GHRH and its receptor leads to activation of the $G_{\mathrm{s}} \alpha$ subunit, stimulation of adenylylcyclase, and increase in intracellular cyclic AMP (cAMP), which in turn promotes the phosphorylation of proteinkinase A, thereby causing cellular proliferation and $\mathrm{GH}$ secretion. Activation of the GHRH-R also triggers the mitogen-activated protein kinase pathway, which may in part contribute to the proliferation of the somatotroph cells (Pombo et al. 2000).

The first evidence that mutations in the GHRH-R gene cause growth hormone deficiency (GHD) came from the little mouse, a naturally occurring murine model for human isolated GHD (IGHD), characterized by autosomal recessive dwarfism and pituitary hypoplasia (Eicher \& Beamer 1976). The little mouse carries a point mutation in the extracellular domain of the receptor that causes a single amino acid substitution (D60G) (Godfrey et al. 1993, Lin et al. 1993). This change impairs the ability of the receptor to bind GHRH (Gaylinn et al. 1999). The first described mutation in the human GHRH-R gene (GHRH-R) was a non-sense mutation in the extracellular domain (codon 72) (Wajnrajch et al. 1996). Since then, several other naturally occurring GHRH-R mutations have been described, including a promoter mutation (Salvatori et al. 2002a), six missense mutations (Salvatori et al. 2001a, Salvatori at al. 2001b, Salvatori et al. 2002a, Salvatori et al. 2002b, Carakushansky et al. 2003), four splice-donor mutations (Salvatori et al. 1999, Roelfsema et al. 2001, Salvatori et al. 2002c, Alba et al. 2004), a second non-sense 
mutations (Salvatori et al. 2002c), and two small deletions (Salvatori et al. 2001b, Horikawa 2002). All these mutations are transmitted as autosomal recessive traits, with the possible exception of one of the small deletions that has been reported to have an in vitro dominant negative effect (Horikawa 2002). All but the missense mutations are expected to cause the receptor to be prematurely truncated or its translation to be out of frame.

The mechanism by which the six single amino acid substitutions (H137L, L144H, A176V, A222E, F242C, and K329E) alter receptor function is not yet determined. In this study, we have examined the in vitro effect of these mutations on receptor expression and function. We demonstrate that the mutations do not alter proper surface expression of the receptor, but they do alter ligand binding.

\section{Materials and Methods}

Plasmid constructs

Using site-directed mutagenesis technique (Kunkel 1985) we introduced each missense mutation $(\mathrm{H} 137 \mathrm{~L}, \mathrm{~L} 144 \mathrm{H}$, A176V, A222E, F242C, K329E) into individual GHRH-R cDNA clones. Plasmids with cDNA's with different epitopes were used in different experiments:

1) Due to the lack of a functioning antibody to the human GHRH-R, for immunoprecipitation experiments we used wildtype (WT) and mutant receptor cDNAs containing the Aequorea victoria green fluorescent protein (GFP) tag (Tarasova et al. 2000) at the carboxy-terminus of the receptor in the pEGFP-N2 plasmid (Clonotech, Palo Alto, CA, USA).

2) For the immunofluorescence experiments, WT cDNA receptor containing the FLAG tag in the $\mathrm{N}$-terminal extracellular domain was kindly donated by Dr Kelly Mayo (Northwestern University, Chicago, IL, USA), and subcloned into pcDNA1.0 expression plasmid (Invitrogen, Carlsbad, CA, USA). cDNA fragments containing each mutation were then inserted in substitution of WT sequences (utilizing an EcoRI site) to obtain all 6 mutant cDNAs containing the extracellular FLAG tag.

3) For cAMP assay and for binding experiments, WT and mutant receptor cDNA cloned in pcDNA 1.0 AMP were used.

\section{Cyclic AMP assay}

In order to compare the response to GHRH of all six mutated receptors, we measured cAMP response to GHRH in Chinese Hamster Ovary (CHO) cells transiently transfected with either the WT or mutant receptor cDNA. Briefly, cells were trypsinized and seeded in 24-well plates at $2 \times 10^{5}$ cells/well in minimum essential medium (MEM) $+10 \%$ fetal bovine serum (FBS) (Life Technologies, Gaithersburg, MD, USA) and transfected immediately using FuGENE 6 transfection reagent (Roche, Indianapolis, IN, USA). Not transfected CHO cells (MOCK) and cells transfected with vector alone served as negative controls. Forty-eight $\mathrm{h}$ after transfection, cells were washed with serum free MEM containing $0.5 \mathrm{mmol} / \mathrm{L}$ isobutylmethylxantine (IBMX) and treated with MEM+IBMX (baseline) or with MEM+IBMX+ forskolin $10^{-5} \mathrm{~mol} / \mathrm{L}$ (Sigma-Aldrich, St Louis, MO, USA) or challenged with MEM + IBMX $+\left[\mathrm{Nle}^{27}\right]-$ GHRH-(1-29) $10^{-8} \mathrm{M}$ or $10^{-9} \mathrm{M}$ or $10^{-10} \mathrm{M}$ (Peninsula Laboratories, Inc, Belmont, CA, USA). After 15 min incubation at $37^{\circ} \mathrm{C}$, total cAMP was extracted by addition of HCL to a final concentration of $0.1 \mathrm{~mol} / \mathrm{l}$ and a cycle of freeze-thawing. Cellular cAMP in the acid extracts was measured by RIA as previously described (Levine et al. 1983). The results are the mean of three separate experiments, each performed in duplicate wells and each well assayed in duplicate using $100 \mu \mathrm{l}$ cell extracts. Results have been normalized to the cAMP response to forskolin and are expressed as picomoles of cAMP produced per well.

\section{Immunoprecipitation}

CHO cells, which do not express endogenous GHRH-R, were grown in 6 well/plates in MEM $+10 \%$ FBS (Invitrogen) and transfected at 60-70\% confluence with $1 \mu \mathrm{g}$ of plasmid GFP-tagged GHRH-R cDNA using FuGENE 6 transfection reagent following manufacturer's recommendations. After $48 \mathrm{~h}$, cells were washed twice with ice-cold PBS, harvested and lysed on ice in RIPA buffer $(1 \mathrm{xPBS}, 1 \%$ Nonidet P-40, 0.5\% sodium deoxycholate, $0 \cdot 1 \% \mathrm{SDS}, 10 \mu \mathrm{g} / \mathrm{ml}$ PMSF, protease inhibitor cocktail) (Sigma-Aldrich). The lysate was clarified by centrifugation $\left(10 \mathrm{~min}\right.$ at $15000 \mathrm{~g}$ at $\left.4{ }^{\circ} \mathrm{C}\right)$ and incubated overnight at $4{ }^{\circ} \mathrm{C}$ with $10 \mu \mathrm{g}$ of mouse anti-GFP agaroseconiugated antibody (Santa Cruz Biotechnology Inc., Santa Cruz, CA, USA). Immunoprecipitates were then washed 3 times with ice cold PBS and resuspended in protein sample buffer. Samples were boiled for $5 \mathrm{~min}$ and protein separated on a $10 \%$ SDS-PAGE gel, followed by transfer onto polyvinylidene difluoride membrane (PVDF) (Immobilon-P, Millipore Corporation, Billerica, MA, USA). The filter was blocked for $1 \mathrm{~h}$ in Tris-buffered saline $+0 \cdot 05 \%$ Tween 20 (TBS-T) (Sigma-Aldrich) $+3 \%$ non-fat dry milk (Bio Rad Lab, Hercules, CA, USA), incubated for $1 \mathrm{~h}$ with mouse anti-GFP antibody (1:5000) (Santa Cruz Biotechnology Inc.), washed extensively in TBS-T. After $1 \mathrm{~h}$ incubation with HRP-conjugated goat anti mouse $\operatorname{IgG}$ (1:3000), and washing in TBS-T, immunoreactivity was detected by enhanced chemiluminescence (ECL kit, Amersham Biosciences, Chalfont St Giles, Buckinghamshire, England) and band size compared with pre-stained protein weight marker (Full Range Rainbow, Amersham Biosciences). All steps were performed at room temperature. 


\section{Immunofluorescence}

In order to detect whether the missense mutation could alter proper receptor expression on the cell surface we performed immunofluorescence experiments with the goal of detecting the presence of extracellular FLAG epitope in non-permeabilized transfected cells.

$\mathrm{CHO}$ cells were grown on glass cover slips and at $50-70 \%$ confluence were transfected with FLAG-tagged GHRH-R cDNA using FuGENE 6 transfection reagent. As control, we used $\mathrm{CHO}$ cells transfected with WT GHRH-R cDNA with an hemoagglutinin (HA)-tag, kindly donated by Dr Kelly Mayo, in the intracellular C-terminus. At 100\% confluence cells were washed three times with PBS and fixed with fresh 2\% paraformaldehyde in PBS $\mathrm{pH} 7 \cdot 4$ for $15 \mathrm{~min}$ at room temperature. After four washing steps with PBS, cells were incubated with fluorescein isothiocyanate (FITC)-conjugated anti-FLAG monoclonal antibody (1:100) (Sigma-Aldrich) for $1 \mathrm{~h}$. $\mathrm{CHO}$ cells transfected with GHRH-R HA-tagged cDNA were incubated with monoclonal anti-HA FITCconjugated antibodies (1:200) (Sigma-Aldrich). Cells were then washed four times with PBS at $\mathrm{pH} 8$ and examined by confocal laser scanning microscopy (LSM 410, Carl Zeiss INC, Oberkochen, Germany) using a $40 \mathrm{x}$ objective lens. All slides were scanned for equivalent times using the same contrast and brightness settings.

\section{Binding assay}

To determine whether the missense mutations would alter ligand binding, binding studies were performed using radiolabelled GHRH and HEK 239 membrane extracts. HEK 239 cells were chosen because binding experiments in $\mathrm{CHO}$ cells had proven to be technically poorly reproducible. Cells were grown in $100 \mathrm{~mm}$ dishes and were transfected at 60-70\% confluence with GHRH-R cDNA, using FuGENE 6 transfection reagent. After 48 h, cells were washed, harvested by centrifugation, and homogenized in ice cold homogenization buffer (Hepes $50 \mathrm{mM}$, $\mathrm{NaCl} 100 \mathrm{mM}$, EDTA $10 \mathrm{mM}$, 0.1 mM EGTA, PMSF $1 \mathrm{mM}$, protease inhibitor cocktail) and $100 \mu \mathrm{M}$ bacitracin (Sigma-Aldrich). Supernatant was removed by centrifugation and membrane pellets were resuspended in binding buffer (TRIS $50 \mathrm{mM}$, EGTA $2 \mathrm{mM}$ ) adding $5 \mathrm{mM}$ of alamethicin (Sigma-Aldrich) for permeabilization. For each sample, one tube was incubated for $1 \mathrm{~h}$ at room temperature with approximately 100000 c.p.m. of Human (1-44)- $\mathrm{NH}_{2}{ }^{125}$ I-GHRH (Amersham Biosciences), and the other with both human (1-44)- $\mathrm{NH}_{2}$ ${ }^{125} \mathrm{I}-\mathrm{GHRH}$ and excess $(1 \mu \mathrm{M})$ 'cold' $\left[\mathrm{Nle}^{27}\right]$ human GHRH (1-29)- $\mathrm{NH}_{2}$. Following $10 \mathrm{~min}$ centrifugation at $15000 \mathrm{~g}$, supernatant with receptor-bound GHRH was assayed using a gamma counter. Counts represent total binding, and the difference between counts in the absence or presence of cold GHRH represents specific binding.
The experiment was repeated three times with three different sets of transfected cells. Results are the means \pm S.D. of the three experiments.

\section{Statistical analysis}

Data were analyzed using SPSS statistical package (SPSS Inc., Chicago, IL, USA), and considered statistically significant if $P<0 \cdot 05$. ANOVA was used to analyze cAMP data. In the binding experiments, the difference between specific and non-specific binding of each single construct was analyzed by independent sample $t$-test, while ANOVA was performed to compare the specific binding among all different mutants, mock-transfected and WT.

\section{Results}

Cyclic AMP assay

Only the cells expressing the WT receptor showed a significant cAMP response to GHRH. The cAMP level in cells expressing the WT receptor was significantly higher compared with all other mutants at $10^{-8}$ and $10^{-9} \mathrm{M}$ GHRH concentrations (Fig. 1). The lack of response to GHRH by the mutant receptors indicates that all the mutations impair the receptor's ability to transmit GHRH signalling.

\section{Immunoprecipitation}

To determine whether the mutated GHRH receptors were translated into mature protein, proteins extracts from $\mathrm{CHO}$ cells transiently transfected with either WT or mutant receptors (or with empty plasmid vector) were immunoprecipitated and analysed by Western blotting.

All six mutated receptors were translated into proteins that showed an electrophoretic mobility of about 70$75 \mathrm{kDa}$ (Fig. 2). The shift in the mobility from the displayed size to the expected molecular weight of about $79 \mathrm{kDa}(54 \mathrm{kDa}$ for the receptor plus $25 \mathrm{kDa}$ for the GFP-tag), is likely due to the electrophoretic conditions affecting the charge of the glycosylated protein, and no difference in size between the WT and mutants was observed. This experiment was repeated three times, with consistent results. Although immunoprecipitation is not a quantitative assay, the levels of protein expression were similar in all mutants, indicating that the mutations do not negatively affect transcriptional or translational mechanisms and did not cause protein degradation.

\section{Immunofluorescence}

To confirm that the receptors are correctly localized into the cell membrane we performed immunofluorescence studies using non-permealized $\mathrm{CHO}$ cells transiently 


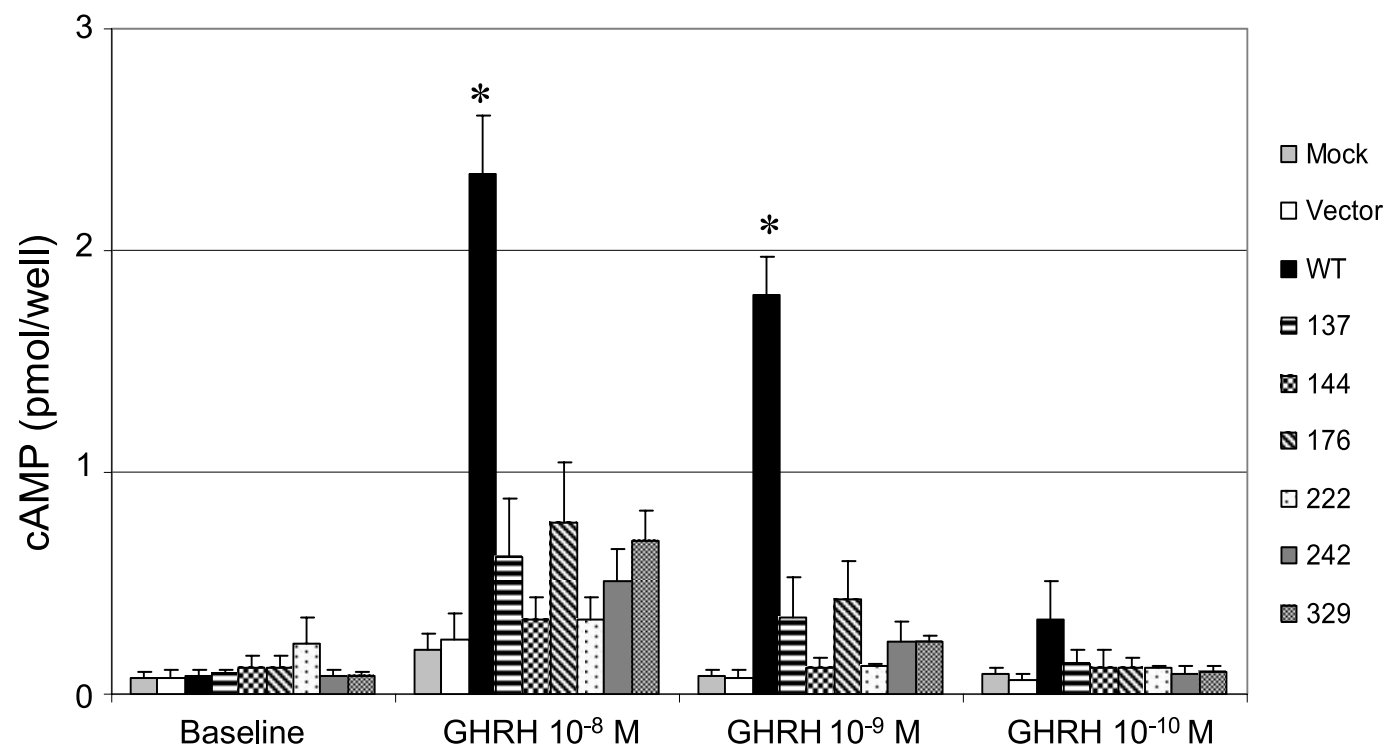

Figure 1 Basal and GHRH-stimulated $\left(10^{-8} \mathrm{M}, 10^{-9} \mathrm{M}, 10^{-10} \mathrm{M}\right)$ intracellular cAMP levels in $\mathrm{CHO}$ cells expressing wild type (WT) and mutated GHRH-R cDNA's. Mock-transfected cells (Mock) and cell transfected with empty vector (Vector) served as controls. The results are the mean of three separate experiments, each performed in duplicate wells, with each well assayed in duplicate. Results are normalized according to cAMP response to forskolin and are expressed as pmol/well. Bars represent S.E.M. ${ }^{*} P<0 \cdot 00001$.

transfected with FLAG-tagged receptor cDNA. Since the FLAG tag is on the extracellular N-terminus of the receptor, only an appropriate localization on the cell membrane would allow interaction with the fluorescent antibody. As shown in Figure 3, using confocal microscopy, no fluorescence was observed either in mocktransfected cells, in cells transfected with vector alone, or in $\mathrm{CHO}$ cells transfected with the intracellular C-terminal HA-tagged receptor.

Contrarilly, cells expressing the WT or mutant receptors showed a comparable pattern of surface fluorescence, indicating that proper translocation towards the cell membrane and insertion of the mutated receptors had occurred.

\section{Binding studies}

Since immunoprecipitation and immunofluorescence studies indicated that the protein is translated in its entire sequence and expressed on the cell surface, we wanted to determine whether the inability of the GHRH to trigger the physiological response to GHRH-R was due to an impaired capacity to bind to its receptor.

Crude membrane pellets were obtained by homogenization and permeabilization from cells expressing either the WT or the mutant GHRH-Rs. Permeabilization with alamethicin was performed in order to enhance specific binding, as previous studies shave demonstrated that functional receptors are present also at internal sites of vesicles (Gaylinn et al. 1994, 1999). GHRH binding was measured by competing assay using ${ }^{125}$ I-human GHRH (Fig. 4). Analysis of specific binding by ANOVA showed that membranes from cells expressing the WT GHRH-R had a significantly higher binding compared with membranes from mock-transfected cells and from cells expressing the mutant receptors $(P<0 \cdot 05)$. Interestingly, when we used independent $t$-test to analyse the response to competitive binding between 'cold' and ${ }^{125}$ I-GHRH in the WT GHRH-R and in each mutated GHRH-R, we found that some specific binding had also occurred in the mutant K329E ( $P<0.002$ vs non-specific binding).

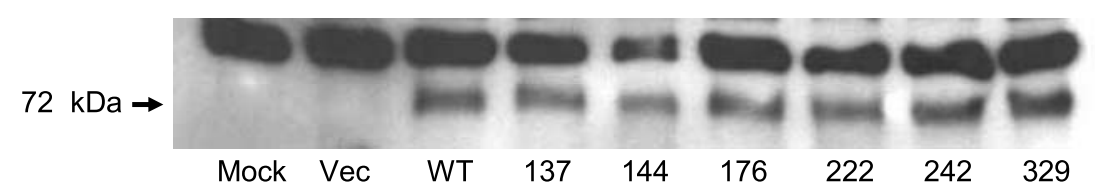

Figure 2 Immunoprecipitation of the mutated receptors transiently transfected into $\mathrm{CHO}$ cells. Protein extract from mock-transfected cells (Mock) and cell transfected with empty vector $(\mathrm{Vec})$ served as negative control, while WT receptor was used as a positive control. The upper band, present in all lanes, is non-specific and likely represents immunoglobulins. 


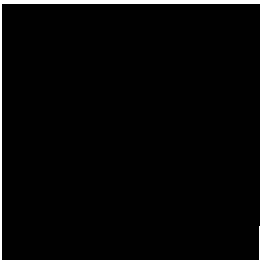

Mock

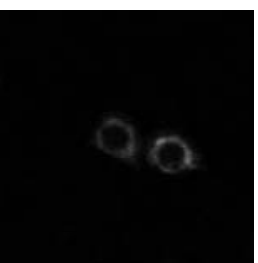

144-FLAG

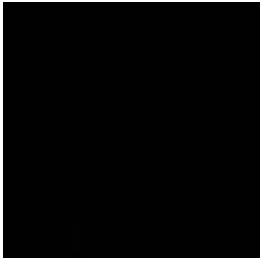

Vec

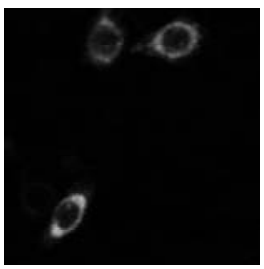

176-FLAG

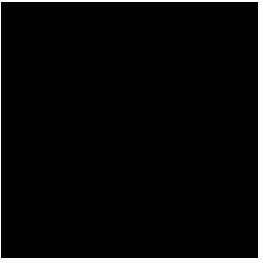

WT-HA

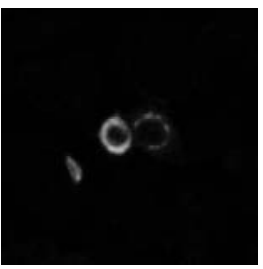

222-FLAG

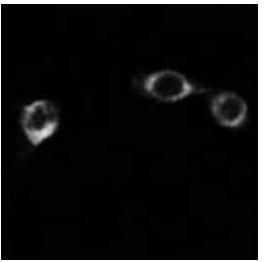

WT-FLAG

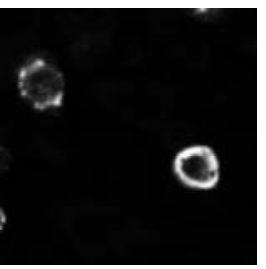

242-FLAG

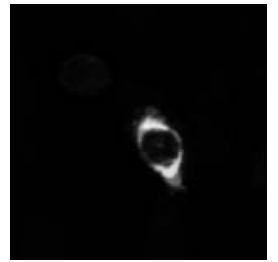

137-FLAG

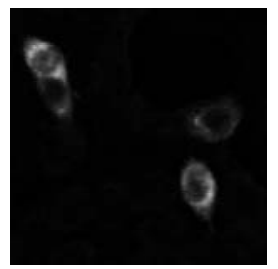

329-FLAG

Figure 3 Immunofluorescence of WT and mutated receptors expressing extracellular FLAG-epitope in non-permealized $\mathrm{CHO}$ cells. Mock-transfected $\mathrm{CHO}$ cells (Mock), $\mathrm{CHO}$ cells transfected with empty vector (Vec) and with WT receptor expressing the intracellular HA-tag (WT-HA) served as negative controls. All images were scanned with a confocal microscope for equivalent times.

\section{Discussion}

The importance of the presence of a functional GHRH-R for the proliferation of somatotroph cells, GH synthesis and secretion, and ultimately for linear growth is demonstrated by the murine model little (lit) mouse, and by several human GHRH-R mutations. Indeed, GHRH-R defects are now recognized as the cause of approximately $10 \%$ of autosomal recessive IGHD (Salvatori et al. 2001a). Studies on the lit GHRH-R (Gaylinn et al. 1999) have shown that the mutant receptor is unable to bind to GHRH.

The GHRH-R belongs to class family B-III of the GPCR superfamily, together with receptors for glucagon, glucagon like peptide-1, secretin, vasoactive intestinal peptide (VIP), gastric inhibitory peptide, and pituitary adenylate cyclase-activating peptide. Using chimeras

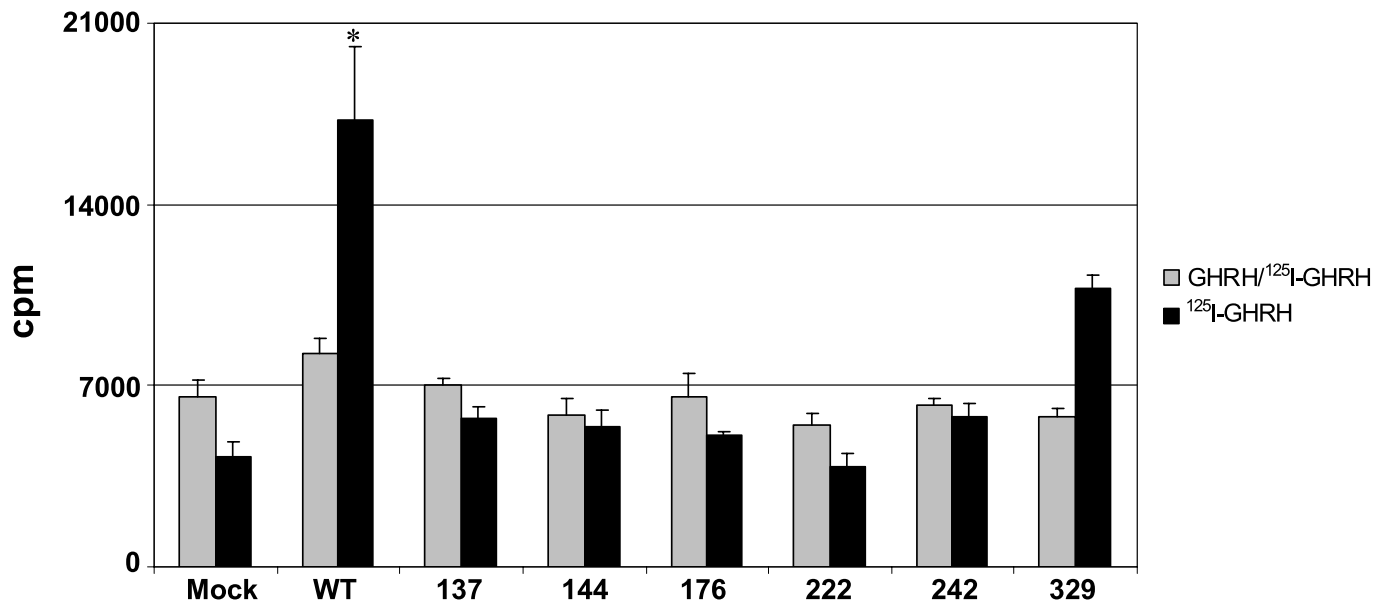

Figure 4 Binding of human ${ }^{125}$ I-GHRH to membranes from mock-transfected HEK 293 cells (Mock) or cells transfected with WT or mutant GHRH-R CDNA. Black bars represent total binding of ${ }^{125} \mathrm{I}-\mathrm{GHRH}$; grey bars describe binding of ${ }^{125} \mathrm{I}-\mathrm{GHRH}$ in presence of $1 \mu \mathrm{M}$ 'cold' competitor GHRH (non-specific binding). Each data point is the mean of three different experiments, each performed in duplicate. Bars represent S.E.M. Analysis by ANOVA indicates that specific binding of WT receptor is statistically significantly higher compared with all the mutated receptors $\left({ }^{\star} P<0 \cdot 02\right)$. 
Table 1 Summary of the location of the six missense mutations and their relevant changes in amino acid sequence and influence on polarity

$\begin{array}{llll} & \text { Change in polarity } & & \text { Location in GHRH-R domains } \\ \text { Amino acid change } & & \\ \text { H137L (histidine } \rightarrow \text { leucine) } & \text { Polar } \rightarrow \text { non polar } & & \text { 1st transmembrane domain } \\ \text { L144H (leucine } \rightarrow \text { histidine) } & \text { Non polar } \rightarrow \text { polar } & & \text { 1st transmembrane domain } \\ \text { A176V (alanine } \rightarrow \text { valine) } & \text { Non polar } \rightarrow \text { non polar } & \text { 2nd transmembrane domain } \\ \text { A222E (alanine } \rightarrow \text { glutamic acid) } & \text { Non polar } \rightarrow \text { polar } & & \text { 3rd transmembrane domain } \\ \text { F242C (phenylalanine } \rightarrow \text { cysteine) } & \text { Non polar } \rightarrow \text { polar } & & \text { 4th transmembrane domain } \\ \text { K329E (lysine } \rightarrow \text { glutamic acid) } & \text { Polar } \rightarrow \text { polar } & & \text { 6th transmembrane domain }\end{array}$

of the GHRH-R and VIP and secretin receptors, DeAlemeida and Mayo (1998) have elegantly shown that both $\mathrm{N}$ - and C-termini of the GHRH-R are necessary for ligand binding and triggering of signalling. The $\mathrm{N}$-terminal extracellular domain plays a fundamental role in initial interaction with the ligand, while residues in the transmembrane domains, in conjunction with the extracellular loops, could have a role in secondary interaction and in determining binding specificity.

All the small deletions, splice mutations or nonsense GHRH mutations described to date either insert a premature stop codon or cause the messenger RNA to be out of frame. Resulting receptors, if translated at all, would lack the C-terminal domain and/or most of the transmembrane domains, possibly preventing the localization of the truncated receptor into the cell membrane or interaction with G proteins. Contrarilly, the GHRH-Rs bearing missense mutations are more likely to be translated into mature protein allowing more extensive studies on how the mutation may interfere with the GHRH signalling pathway. Receptor malfunction could be due to instability and early degradation of the mature protein, improper folding, alterations in intracellular transport or insertion into cell membrane, or in binding of the ligand. Although there is evidence that GPCR's can exist as dimers, to date no mutation has been found that alters dimerization (Milligan 2004).

Our group has reported six naturally occurring missense mutations that cause familial autosomal recessive IGHD. The six amino acids that are mutated are conserved in all mammalian GHRH-Rs (human, rat, pig, bovine, and ovine) cloned to date (Horikawa et al. 2001), pointing to their importance in receptor function and confirming that these changes are not polymorphisms. Indeed, when expressed in eukaryotic cells, the mutated receptors are not able to activate the intracellular messenger cascade.

To investigate the expression of the mutated proteins, we transiently transfected $\mathrm{CHO}$ cells either with WT or mutant GHRH-R cDNA tagged with an intracellular GFP-tag. Receptors were immunoprecipitated and detected by Western blot. All mutant receptors are expressed and are of identical size as the WT. The degree of expression seems not to be altered, suggesting that the mutations do not interfere with posttranscriptional events. The size of band displayed on the Western blot is not in perfect accordance with the expected size of $79 \mathrm{kDa}$, which could be due to electrophoretic conditions affecting the charge of the proteins and therefore their mobility. Another possible explanation is that the glycosylation of human GHRH-R expressed in HEK 293 is altered (Gaylinn et al. 1994). Nevertheless, the electrophoretic migration of the mutant receptors is identical to the one of the WT protein.

The expression of the mutated receptors is also confirmed by the results of the immunofluorescence studies. All mutant receptors containing an extracellular FLAG-tag display immunofluorescence in non-permeabilized cells, indicating that the receptor is properly transferred through the Golgi apparatus to the cell surface.

Once we determined that the mutated receptors were properly expressed on the cell surface, we investigated their ability to bind to labelled GHRH. Binding studies revealed that all the mutated receptors had reduced ligand binding compared with WT receptor. The K329E mutation seems to retain some binding capacity, as shown by the difference between specific and non-specific binding, but its binding ability remained significantly lower than the wild type. The K329E mutant does not cause any rise in intracellular cAMP. We can only speculate on the reason of this finding. As shown in Table 1 all of the six mutations are located within the transmembrane domains and four (H137L, L144H, A222E, and F242C) produce modifications in the degree of solubility of the amino acid within the lipid layer of the cell membrane. It is conceivable that a change of polarity causes alterations in proper protein folding and receptor function. Since the mutation K329E causes the change from one polar amino acid to another (lysine to glutamic acid) it is possible that the conformation of the protein is conserved to a point that would still allow some degree of ligand binding but not further signalling.

Unfortunately, to date little is known regarding the role of specific residues in the transmembrane domains of class B GPCR's and limited data are available on the mechanism through which mutations in these regions may affect receptor function. 
To determine how the amino acid changes cause the inability of the receptor to bind the ligand would require the creation of three-dimensional models analysing how the single amino acid changes affect the tertiary structure of the protein.

In conclusion, we have shown that the six naturally occurring and disease-causing missense GHRH-R mutations identified to date allow proper surface expression of the receptor. They cause the receptor to be unable to bind to $\mathrm{GHRH}$, impairing its ability to transmit intracellular signalling and ultimately to stimulate $\mathrm{GH}$ secretion.

\section{Acknowledgments}

This work was supported by NIH grant 1R03 HD042465-01 (R S). We wish to thank Dr Kelly Mayo (Northwestern University, Chicago, IL, USA) for kindly providing the FLAG-tagged GHRH-R cDNA and the HA-tag. The authors declare that there is no conflict of interest that would prejudice the impartiality of this scientific work.

\section{References}

Alba M, Hall CM, Andrew J, Whatmore AJ, Clayton PE, Price DA \& Salvatori R 2004 Variability in anterior pituitary size within members of a family with GH deficiency due to a new splice mutation in the GHRH receptor gene. Clinical Endocrinology $\mathbf{6 0}$ 470-475.

Carakushansky M, Whatmore AJ, Clayton PE, Shalet SN, Gleeson HK, Price DA, Levine MA \& Salvatori R 2003 A new missense mutation in the growth hormone-releasing hormone receptor gene in familial isolated GH deficiency. European Journal of Endocrinology $14825-30$.

DeAlmeida VI \& Mayo KE 1998 Identification of binding domains of the growth hormone-releasing hormone recpetor by analysis of mutant and chimeric receptor proteins. Molecular Endocrinology 12 $750-765$.

Eicher EM \& Beamer WG 1976 Inherited ateliotic dwarfism in mice. Characteristics in the mutation, little, on chromosome 6. Journal of Heredity 67 87-91.

Gaylinn BD, Lyons CE, Zysk JR, Clarke IJ \& Thorner MO 1994 Photoaffinity cross-linking to the pituitary receptor for growth hormone releasing-factor. Endocrinology 135 950-955.

Gaylinn BD, DeAlmeida VI, Lyons CE, Wu KC, Mayo KE \& Thorner MO 1999 The mutant growth hormone releasing hormone $(\mathrm{GHRH})$ receptor of the little mouse does not bind GHRH. Endocrinology 140 5066-5074.

Godfrey P, Rahal JO, Beamer WG, Copeland NG, Jenkins NA \& Mayo KE 1993 GHRH receptor of little mice contains a missense mutation in the extracellular domain that disrupts receptor function. Nature Genetics 4 227-232.

Horikawa R 2002 Isolated GH deficiency due to inactivating mutation of GHRH receptor Nippon Rinsho 60 297-305.

Horikawa R, Gaylinn BD, Lyons Jr CE \& Thorner MO 2001 Molecular cloning of ovine and bovine growth hormone releasing hormone receptor: the ovine receptor is C-terminally truncated. Endocrinology 142 2660-2668.
Kunkel TA 1985 Rapid and efficient site-specific mutagenesis without phenotypic selection. PNAS 82 488-492.

Levine MA, Eil C, Downs Jr RW \& Spiegel AM 1983 Deficient guanine nucleotide regulatory unit activity in cultured fibroblast membranes from patients with pseudohypoparathyroidism type I. A cause of impaired synthesis of $3^{\prime}, 5^{\prime}$-cyclic AMP by intact and broken cells. Journal of Clinical Investigation 72 316-324.

Lin SC, Lin CR, Gukovsky I, Lusis AJ, Sawchenko PE \& Rosenfeld MG 1993 Molecular basis of the little mouse phenotype and implications for cell type-specific growth. Nature 364 208-213

Milligan G 2004 G protein-coupled receptor dimerization: function and ligand pharmacology. Molecular Pharmacology 66 1-7.

Muller EE, Locatelli V \& Cocchi D 1999 Neuroendocrine control of growth hormone secretion. Physiology Reviews 79 511-607.

Pombo CM, Zalvide J \& Gaylinn B 2000 Growth hormone-releasing hormone stimulates mitogen activated protein kinase. Endocrinology $1412113-2119$.

Roelfsema F, Biermasz NR, Veldman RG, Veldhuis JD, Frolich M, Stokvis-Brantsma WH \& Wit JM 2001 Growth hormone (GH) secretion in patients with an inactivating defect of the GH-releasing hormone $(\mathrm{GHRH})$ receptor is pulsatile: evidence for a role for nonGHRH inputs into the generation of GH pulses. Journal of Clinical Endocrinology and Metabolism 86 2459-2464.

Salvatori R, Hayashida CY, Aguilar-Oliveira MH, Phillips JA III, Souza AH, Gondo RG, Toledo SPA, Conceicao MM, Prince M, Baumann G, Maheshwari H \& Levine MA 1999 Familial Dwarfism due to a novel mutation of the growth hormone-releasing hormone receptor gene. Journal of Clinical Endocrinology and Metabolism 84 917-923.

Salvatori R, Fan X, Phillips JA III, Espigares R, Martin de Lara I, Freeman K, Plotnick L, Al-Shawl A \& Levine MA 2001a Three new mutations in the gene for growth hormone $(\mathrm{GH})$-releasing hormone receptor in familial isolated GH deficiency type IB. Journal of Clinical Endocrinology and Metabolism 86 273-279.

Salvatori R, Fan X, Phillips JA III, Prince M \& Levine MA $2001 b$ Isolated growth hormone $(\mathrm{GH})$ deficiency due to compound heterozygosity for two new mutations in the GH-releasing hormone receptor gene. Clinical Endocrinology 54 681-687.

Salvatori R, Fan X, Mullis PE, Haile A \& Levine MA 2002a Decreased expression of the GHRH receptor gene due to a mutation in a Pit-1 binding site. Molecular Endocrinology 16 450-458.

Salvatori R, Aguiar-Oliveira MH, Monte LVB, Hedges L, Santos NL, Pereira RMC \& Phillips III JA $2002 b$ Detection of a recurring mutation in the human growth hormone- releasing hormone receptor gene. Clinical Endocrinology 57 77-80.

Salvatori R, Fan X, Veldhuis J \& Couch R 2002c Serum GH response to pharmacological stimuli and physical exercise in two siblings with two new inactivating mutations in the GH-releasing hormone receptor gene. European Journal of Endocrinology 147 591-597.

Tarasova NI, Stauber RD \& Wank SA 2000 Characterization of receptor trafficking with green fluorescent protein. In Regulation of $G$ protein-coupled receptor function and expression. pp 253-272. Ed JL Benovic. New York: John Wiley and Sons.

Wajnrajch MP, Gertner JM, Harbison MD, Chua SC Jr \& Leibel RL 1996 Nonsense mutation in the human growth hormone-releasing hormone receptor causes growth failure analogous to the little (lit) mouse. Nature Genetics 12 88-90.

Received 16 June 2005

Accepted 28 June 2005

Made available online as an Accepted Preprint

13 July 2005 